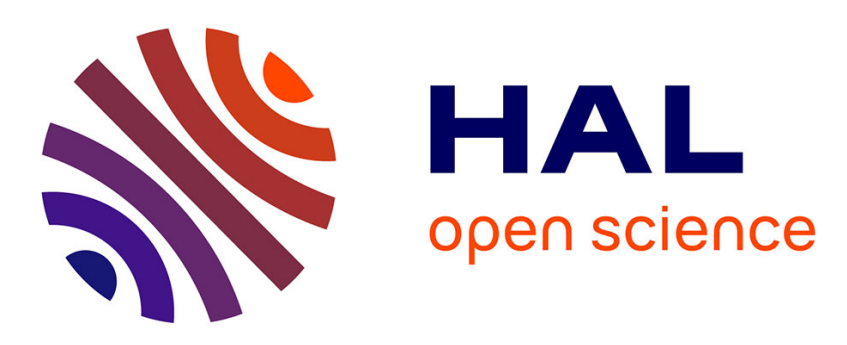

\title{
Microstructure and Mechanical Properties of a-CN x Films Prepared by Bias Voltage Assisted PLD with Carbon Nitride Target
}

Xiao Huo Zheng, Fang-Er Yang, Li Chen, Zhan-Ling Chen, Ren-Guo Song, Xianghua Zhang

\section{To cite this version:}

Xiao Huo Zheng, Fang-Er Yang, Li Chen, Zhan-Ling Chen, Ren-Guo Song, et al.. Microstructure and Mechanical Properties of a-CN x Films Prepared by Bias Voltage Assisted PLD with Carbon Nitride Target. Surface and Coatings Technology, 2014, 258, pp.716-721. 10.1016/j.surfcoat.2014.08.009 . hal-01088708

\section{HAL Id: hal-01088708 \\ https://hal-univ-rennes1.archives-ouvertes.fr/hal-01088708}

Submitted on 28 Nov 2014

HAL is a multi-disciplinary open access archive for the deposit and dissemination of scientific research documents, whether they are published or not. The documents may come from teaching and research institutions in France or abroad, or from public or private research centers.
L'archive ouverte pluridisciplinaire HAL, est destinée au dépôt et à la diffusion de documents scientifiques de niveau recherche, publiés ou non, émanant des établissements d'enseignement et de recherche français ou étrangers, des laboratoires publics ou privés. 


\title{
Microstructure and Mechanical Properties of a-CN $\mathrm{CN}_{x}$ Films Prepared by Bias Voltage Assisted PLD with Carbon Nitride Target
}

Xiao-hua Zheng ${ }^{1 *}$, Fang-er Yang ${ }^{1}$, Li Chen ${ }^{2}$, Zhan-ling Chen ${ }^{1}$, Ren-guo Song ${ }^{3}$, Xiang-hua Zhang $^{4}$

1. College of materials science and engineering, Zhejiang University of Technology, No.18 Chaowang Road, Hangzhou 310014, China

2. College of mechanical engineering, Zhejiang University of Technology, No.18 Chaowang Road, Hangzhou 310014, China

3. School of materials science and engineering, Changzhou University, Gehu Road, Changzhou 213164,

\section{China}

4. Laboratoire de Verres et Céramiques, Université de Rennes 1, Avenue du Général Leclerc, Rennes Cedex 35042, France

\begin{abstract}
Amorphous carbon nitride $\left(\mathrm{a}-\mathrm{CN}_{x}\right)$ films were deposited on silicon substrates using pulsed laser deposition technique (PLD) with a carbon nitride target and a negative bias voltage up to $-120 \mathrm{~V}$. The microstructure, chemical composition, bonding configuration and mechanical properties of the films were characterized by using scanning electron microscopy (SEM), X-ray diffraction (XRD), X-ray photoelectron spectroscopy (XPS), Raman spectroscopy, nanoindentation and ball-on-disc abrasion test. The results show that the negative bias voltage promotes the formation of $\mathrm{sp}^{3}$ hybridization bonding and leads to a great improvement of nitrogen content (up to 38 at.\%) in the films. With an increasing bias voltage from $-40 \mathrm{~V}$ to $-120 \mathrm{~V}$, the nitrogen content and the fraction of $\mathrm{sp}^{3}$ hybridization bonding
\end{abstract}

Corresponding author. Tel. +86571 88320479. Fax: +8657188320130

E-mail: zhengxh@zjut.edu.cn (X. H. Zheng) 
decrease, leading to an increasing graphitization of the films. A direct dependence of the hardness on the content of $\mathrm{sp}^{3}$ hybridization bonding is observed. The friction coefficient of the films ranges from 0.20 to 0.28 . The film deposited at a bias voltage of $-40 \mathrm{~V}$ presents the highest hardness value of $8.3 \mathrm{GPa}$.

Keywords: Carbon nitride; XPS; Raman; friction and wear; pulsed laser deposition 


\section{Introduction}

Since Liu and Cohen [1] theoretically predicted that the crystalline phase $\beta-C_{3} N_{4}$ could have bulk modulus and hardness comparable to or even higher than those of diamond, $\mathrm{CN}_{x}$ films have received considerable interest. According to a large number of publications [2-9], $\mathrm{CN}_{x}$ films are proved to be amorphous and the nitrogen content is far from the stoichiometric concentration ( $\sim 57$ at.\%). Moreover, the mechanical properties of the films fluctuate in a large scale [10-13] and the thermal stability is poor due to its low decomposition temperature [1416]. Nowadays, it is a tremendous challenge to fabricate a crystalline film that exhibits superhigh hardness in order to check the correctness of the theoretical prediction with of course tremendous application potential, though a few $\mathrm{CN}_{x}$ films of high nitrogen concentration up to $\sim 50$ at. $\%$ (or N/C ratio $\sim 1.0$ ) have been synthesized by chemical vapor deposition (CVD) [17-18], electrodeposition [19], magnetron sputtering (MS) [20] and pulsed laser deposition (PLD) [21-23], etc. The optimal condition for the crystallization of carbon nitride is still to be found.

In recent years, our team has developed a series of pulsed laser deposited $\mathrm{CN}_{x}$ films by using a carbon nitride target instead of widely used graphite target. The results show that the nitrogen concentration of the films is greatly increased in comparison with those of conventional films deposited with graphite target, the growth rate of the films is more than twice as high as that of the conventional films and the size of particle lumps on the surface as well as the roughness of the films are reduced. However, the films exhibit a large value of $x\left(\mathrm{sp}^{2} \mathrm{C}-\mathrm{N}\right) / x\left(\mathrm{sp}^{3} \mathrm{C}-\mathrm{N}\right)\left(\right.$ i.e., the mole content ratio of $\mathrm{sp}^{2} \mathrm{C}-\mathrm{N}$ bonding to $\mathrm{sp}^{3} \mathrm{C}-\mathrm{N}$ bonding) and lower mechanical properties compared to the conventional films. Due to the complexity of 
bonding configuration in $\mathrm{CN}_{x}$ films, it is quiet hard to conclude that a higher level of nitrogen content leads to lower mechanical properties. The importance of bonding configuration should be considered in the elaboration of high performance films.

It is well-known that the DC negative bias voltage technique is widely used in the magnetron sputtering deposition of films $[24,25]$. The results show that the bias voltage dramatically affects the bonding configuration of carbon with/or nitrogen in the films [26, 27]. Consequently, by combining a negative bias voltage and the PLD technique, we can expect to alter efficiently the bonding configuration of the $\mathrm{CN}_{x}$ films deposited with carbon nitride target. In the present work, the $\mathrm{CN}_{x}$ films were fabricated in the deposition system. The composition, the chemical bonding states and the mechanical properties of the films were investigated by comparison with the films deposited using graphite target with the same process parameters.

\section{Experimental conditions}

\subsection{Preparation of films and the target}

$\mathrm{CN}_{x}$ films were deposited at room temperature by using a pulsed $\mathrm{KrF}$ excimer laser (Lambda Physik COMPex pro-201, wavelength of $248 \mathrm{~nm}$, pulse duration of $25 \mathrm{~ns}$, repetition rate of $10 \mathrm{~Hz}$, and laser flux of $\sim 6.7 \mathrm{~J} / \mathrm{cm}^{2}$ ) with a carbon nitride target and a DC bias voltage value (i.e., $V_{\mathrm{b}}$ ) of $0 \mathrm{~V},-40 \mathrm{~V},-80 \mathrm{~V},-120 \mathrm{~V}$, respectively. The negative bias voltage was applied to the sample holder insulated from the grounded chamber and the target. Polished $\mathrm{Si}<100>$ wafers were used as substrates and mounted onto the sample holder after being chemically cleaned. During the deposition, the pressure of $\mathrm{N}_{2}$ (reacting gas, $99.999 \%$ in purity) was set at $5 \mathrm{~Pa}$ and the target-to-substrate distance was $45 \mathrm{~mm}$. The target and the 
substrate were rotated to ensure the uniform erosion of the target and to improve the uniformity of the films. With a deposition duration of 20 minutes, the thickness of the films ranged from 1.1 to1.3 $\mu \mathrm{m}$. The $\mathrm{CN}_{x}$ films for comparison purposes (i.e., the reference films) were deposited by using graphite target $\left(2.15 \mathrm{~g} \mathrm{~cm}^{-3}\right.$ in density) with the same process parameters as the films deposited with carbon nitride target. The film thickness ranged from 0.3 to $0.5 \mu \mathrm{m}$.

The carbon nitride target was also fabricated by PLD technique with a silicon wafer substrate $(50.8 \mathrm{~mm}$ in diameter and $420 \mu \mathrm{m}$ in thickness). Its deposition condition was the same as that of the reference films, except for the bias voltage of $0 \mathrm{~V}$ and the deposition duration of 520 hours. The thickness, density and the nitrogen concentration of the carbon nitride target are respectively $0.35 \mathrm{~mm}, 1.63 \mathrm{~g} \mathrm{~cm}^{-3}$ and 24.5 at.\%.

\subsection{Film characterization}

The surface morphology and crystalline state of the films were observed by using scanning electron microscopy (SEM, Hitachi S-4700, with an accelerating voltage of $15 \mathrm{kV}$ ) and X-ray diffraction (XRD, Rigaku D/Max $1152550 \mathrm{PC}, \mathrm{Cu} \mathrm{K \alpha}$, at an incidence angle of $3^{\circ}$, with a step of $0.02^{\circ}$ ). The XPS experiments were carried out with a Kratos AXIS Ultra DLD spectrometer, equipped with standard Al Ka excitation source ( $h v=1486.7 \mathrm{eV})$. The x-ray gun was operated at $300 \mathrm{~W}$ and photoelectron spectra were collected under constant pass energy of $20 \mathrm{eV}$ for the analyzer. The energy calibration was referenced to the $\mathrm{Cu} 2 \mathrm{p}_{3 / 2}$ line at 932.67 $\mathrm{eV}$ and the $\mathrm{Ag} 3 \mathrm{~d}_{5 / 2}$ line at $368.26 \mathrm{eV}$. After background subtraction of Shirley, the spectra were fitted with Lorentzian-Gaussian functions.

Raman scattering measurements (LabRAM HR UV) were performed by collecting the 
backscattering radiation at excitation wavelength of $632.8 \mathrm{~nm}$ in the wave-number range of $800-2000 \mathrm{~cm}^{-1}$. After background subtraction by means of linear interpolation, the spectra were fitted with Lorentzian-Gaussian function. Nanoindentation tests were carried out on a Hysitron TI 900 triboindenter with Berkovich indenter and maximum load at $1 \mathrm{mN}$ to evaluate the mechanical properties of the $\mathrm{CN}_{x}$ films. Each film was measured 20 times and the mean values of hardness and elastic modulus were calculated. The abrasion tests were carried out on a ball-on-disc tribometer (HT-600). The testing parameters were set as the following: $\mathrm{Si}_{3} \mathrm{~N}_{4}$ ball $(5 \mathrm{~mm}$ in diameter), normal load at $0.49 \mathrm{~N}$, sliding velocity at $0.176 \mathrm{~m} / \mathrm{s}$, test duration at $15 \mathrm{~min}$, and relative humidity at $60 \sim 67 \%$. The average values of the recorded instantaneous friction coefficient were used.

\section{Results and discussion}

\subsection{Composition and chemical structure}

The XRD results show that the films are amorphous. The typical surface morphology of the films is shown in Fig.1. It is similar for all $\mathrm{CN}_{x}$ films obtained with different bias voltages. This could be attributed to the rather weak bombardment effect of the PLD-ed species compared to Argon ions commonly used in ion etching technique. The kinetic energy of the former is about $\left(V_{\mathrm{b}}+20 \sim 40\right) \mathrm{eV}$ and the later is usually greater than $500 \mathrm{eV}$.

Fig.2 shows the detailed $\mathrm{C}_{1 \mathrm{~s}}$ and $\mathrm{N}_{1 \mathrm{~s}}$ XPS spectra of the films and the reference films as a function of bias voltage. According to some recent publications [28-32], the $\mathrm{C}_{1 \mathrm{~s}}$ spectra (Fig. 2a) have been decomposed with Gaussian-Lorentzian distribution functions into five core level $\mathrm{C}_{i}(\mathrm{i}=1,5): \mathrm{C}_{1} 284.5 \pm 0.1 \mathrm{eV}, \mathrm{C}_{2} 285.3 \pm 0.2 \mathrm{eV}, \mathrm{C}_{3} 286.3 \pm 0.1 \mathrm{eV}, \mathrm{C}_{4} 287.4 \pm 0.2 \mathrm{eV}$, and $\mathrm{C}_{5} 288.9 \pm 0.4 \mathrm{eV}$. The first two peaks are assigned as carbon coordinated carbon bonds 
(respectively $\mathrm{sp}^{2} \mathrm{C}-\mathrm{C}$ and $\mathrm{sp}^{3} \mathrm{C}-\mathrm{C}$ ). Due to the substitution of nitrogen for carbon in the carbon network, the $\mathrm{C}-\mathrm{N}$ bonding configurations are presented at higher binding energies due to the higher electronegativity of nitrogen [33]. The contribution at $286.3 \mathrm{eV}$ corresponds to the $\mathrm{sp}^{2} \mathrm{C}-\mathrm{N}$ hybridization bonding, while the peak at $287.4 \mathrm{eV}$ is attributed to the $\mathrm{sp}^{3} \mathrm{C}-\mathrm{N}$ hybridization bonding. Finally, the peak $\mathrm{C}_{5}$ is a characteristic of the $\mathrm{C}-\mathrm{O}$ bonding configurations. In Fig.2b, the $\mathrm{N}_{1}$ peak component $(\sim 398.6 \pm 0.1 \mathrm{eV})$ has been assigned to a $\operatorname{sp}^{3} \mathrm{C}-\mathrm{N}$ hybridization bonding, meanwhile the $\mathrm{N}_{2}$ peak $(\sim 400.0 \pm 0.1 \mathrm{eV})$ corresponds to a $\mathrm{sp}^{2} \mathrm{C}-\mathrm{N}$ hybridization bonding, and the $\mathrm{N}_{3}$ peak $(\sim 402.1 \pm 0.2 \mathrm{eV})$ corresponds to $\mathrm{N}-\mathrm{O}$ bonding.

According to the deconvoluted results from the spectra above, the mole fraction of valence bonds can be determined, and then the ratio of $x\left(s p^{2}\right)$ to $x\left(s p^{3}\right)$ (calculated from $\mathrm{C} 1 \mathrm{~s}$ spectrum) and $x\left(s p^{2} \mathrm{C}-\mathrm{N}\right)$ to $x\left(s p^{3} \mathrm{C}-\mathrm{N}\right)$ (calculated from $\mathrm{N} 1 \mathrm{~s}$ spectrum) are illustrated as a function of bias voltage in Fig.3, where $x\left(s p^{2}\right)$ is the mole fraction of $s p^{2}$ bond, $x\left(s p^{3}\right)$ the mole fraction of $s p^{3}$ bond, $x\left(s p^{2} \mathrm{C}-\mathrm{N}\right)$ the mole fraction of $s p^{2} \mathrm{C}-\mathrm{N}$ bond, and $x\left(s p^{3} \mathrm{C}-\mathrm{N}\right)$ the mole fraction of $s p^{3} \mathrm{C}-\mathrm{N}$ bond. From Fig.3, both the ratio $x\left(s p^{2}\right) / x\left(s p^{3}\right)$ and $x\left(s p^{2} \mathrm{C}-\mathrm{N}\right) / x\left(s p^{3} \mathrm{C}-\mathrm{N}\right)$ of the films are strongly dependent on bias voltage, and the corresponding minima of 1.78 and 1.07 are obtained at $-40 \mathrm{~V}$. It is suggested that the films deposited at $-40 \mathrm{~V}$ exhibit the highest mole fractions of both the $\mathrm{sp}^{3}$ hybridization bonding and the $s p^{3} \mathrm{C}-\mathrm{N}$ bonding. Both minima are obviously lower than those of the reference films (2.43 and 1.36 , respectively). This indicates that the use of carbon nitride target can remarkably improve the content of $\mathrm{sp}^{3}$ hybridization bonding in the films. From Fig.3, we can also conclude that the bias voltage has an important influence on the bonding structure and the optimum bias voltage is around $-40 \mathrm{~V}$ for promoting the formation of $\mathrm{sp}^{3}$ hybridization bonding in the films. 
Fig. 4 shows the effect of the bias voltage on the nitrogen content of the $\mathrm{CN}_{x}$ films. With the increase of bias voltage from $0 \mathrm{~V}$ to $-120 \mathrm{~V}$, the nitrogen content of the films peaks at $-40 \mathrm{~V}(\sim 38$ at.\%) and is significantly higher than that of the reference films by $9 \sim 11$ at.\%. Accordingly, we can conclude that the use of carbon nitride target is beneficial to the formation of highly nitrogen-contained $\mathrm{CN}_{x}$ films. Due to its relatively low density and heat of evaporation compared to graphite target, the carbon nitride target brings brighter and larger size plume during the ablation and yields a higher concentration of the species $\left(e . g ., \mathrm{C}^{+}, \mathrm{C}_{2}^{+}\right.$, $\mathrm{CN}, \mathrm{CN}^{+}, \mathrm{C}_{2} \mathrm{~N}_{2}, \mathrm{~N}^{+}, \mathrm{N}_{2}^{+}$) [34-36], which provoke more collisions among them. Under the condition without bias voltage, when carbon nitride target is sputtered physically, it is expected to have better composition transfer (therefore nitrogen content) from the target to the film. As a consequence of the chemical sputtering effect, the active carbon-containing species react with nitrogen, leading to the production of some $\mathrm{CN}$ radicals and $\mathrm{C}_{2} \mathrm{~N}_{2}$ which provide additional nitrogen atoms for the construction of $\mathrm{CN}_{x}$ film. This is of course helpful for increasing nitrogen content in the film. This mechanism may explain why the nitrogen content in the films deposited with carbon nitride target is higher than that of its target. Now consider the film deposition under a bias voltage. On one hand, bias voltage provokes an increase of the kinetic energy of positively ionized species and consequently an increase of the chemical reactivity of these species. Therefore, the reaction between carbon-containing species and ambient nitrogen becomes easier and more nitrogen atoms can be incorporated into the film. On the other hand, bias voltage facilitates the refocusing on the film surface, of all positively ionized species (e.g. $, \mathrm{N}^{+}, \mathrm{N}_{2}{ }^{+}, \mathrm{CN}^{+}, \mathrm{C}_{2} \mathrm{~N}_{2}^{+}$) diverging from the deposition direction due to the collisions among the species. This refocusing will lead to an increase of the nitrogen content of the film. However, under the influence of the bias voltage, the positively ionized species in 
the plasma are accelerated and driven towards the substrate and induce the actions of bombardment and sputtering on the film surface. At higher bias voltages, more intense bombardment of the species heats the substrate to a higher temperature, which releases the volatile nitrogen-containing molecules (e.g., $\mathrm{N}_{2}, \mathrm{C}_{2} \mathrm{~N}_{2}$ ) from the films [14-17]. Therefore, a further increase in bias voltage results in a reduction of nitrogen incorporation. Moreover, the size of the plume in the normal direction of target surface increases with an increase in bias voltage. Once the bias voltage exceeds a critical threshold (for instance, $-550 \mathrm{~V}$ in this case), the leading portion of the plume will be directly in contact with the films and leads to the destruction of the films by its high temperature.

Compared to the deposition of the reference films, more intense collision during the deposition will result in a decrease of the kinetic energy of the active species. And this will weaken the action of sputtering and bombardment, leading to a lower deposition temperature. It is well-known that $\mathrm{sp}^{3}$ hybridization bonding is prone to be formed in the temperature range of $150-400{ }^{\circ} \mathrm{C}$ and it is also demonstrated that the fraction of $\mathrm{sp}^{3}$ hybridization bonding decreases with bias voltage (Fig.3). Therefore we conclude that the higher fraction of $\mathrm{sp}^{3}$ bonding of the films can be attributed to a relatively low deposition temperature and to an appropriate kinetic energy with which the deposited species arrive on the film surface.

Fig. 5 shows the Raman spectra of the films. The measured spectrum of all films exhibits two asymmetric peaks with Gaussian functions similar to the Raman analysis of amorphous carbon in the range of $800-2000 \mathrm{~cm}^{-1}$. The peak centered at $\sim 1350 \mathrm{~cm}^{-1}$ is a disordered band ( $\mathrm{D}$ band) originating from the $\mathrm{A}_{1 \mathrm{~g}}$ breathing modes of $\mathrm{sp}^{2}$ ring (hexagonal or graphitic) structures or the destruction of carbon networks by nitrogen substitution. The other peak centered at $\sim 1530 \mathrm{~cm}^{-1}$ is a graphitic band (G band) and attributed to the stretching of pairs of 
$\mathrm{sp}^{2}$ atoms with vibrations ( $\mathrm{E}_{2 \mathrm{~g}}$ modes) [37,38]. After the deconvolution of Raman spectra of the $\mathrm{CN}_{x}$ films, the detailed structural information of the films can be understood.

Fig.6 shows the dependence of the $I_{\mathrm{D}} / I_{\mathrm{G}}$ (i.e., the integral intensity ratio of $\mathrm{D}$ band to $\mathrm{G}$ band), the full width at half maximum of both $\mathrm{D}$ band and $\mathrm{G}$ band (i.e., $\mathrm{FWHM}_{\mathrm{D}}$ and $\mathrm{FWHM}_{\mathrm{G}}$ ), and the position of both bands with bias voltage. As observed from Fig.6a, the slight shift of the G and D peak positions towards a higher wave band with the increase in bias voltage of $\mathrm{CN}_{x}$ films indicates an increase in the size of $\mathrm{C} \mathrm{sp}{ }^{2}$ domains [39]. Meanwhile, the $\mathrm{FWHM}_{\mathrm{G}}$ of the films tends to decrease with higher bias voltage and this can be attributed to the increase of the cluster size $[40]$. The $I_{\mathrm{D}} / I_{\mathrm{G}}$ ratio is a good structural indicator for $\mathrm{CN}_{x}$ films, since both $I_{\mathrm{D}}$ and $I_{\mathrm{G}}$ are sensitive to the size of the micro-domains. In fact, $I_{\mathrm{D}}$ and $I_{\mathrm{G}}$ decrease as the grain size increases [41]. It can be seen that the $I_{\mathrm{D}} / I_{\mathrm{G}}$ ratio decreases at first and then increases with increasing bias voltage and the minimum $I_{\mathrm{D}} / I_{\mathrm{G}}$ ratio of 1.85 is obtained at -40 V. According to A. Alkhawwam et al. [42] and A. C. Ferrari et al. [43], we can conclude that the increase in $I_{\mathrm{D}} / I_{\mathrm{G}}$ ratio, the shift of the $\mathrm{G}$ and $\mathrm{D}$ peak positions towards higher frequencies, and the decrease in $\mathrm{FWHM}_{\mathrm{G}}$ with the increase of bias voltage can be attributed to the decrease in $\mathrm{sp}^{3}$ bonding fraction and to the increase in size of graphitic cluster. At a bias voltage of $-120 \mathrm{~V}$, the high value of $I_{\mathrm{D}} / I_{\mathrm{G}}$ and $\mathrm{FWHM}_{\mathrm{D}}$ of the film is attributed to the increasing bond angle disorder and indicate the increased degree of carbon network disorder $[44,45]$. As for the reference films (Fig.6b), the higher values of the position of D and G bands and of the $I_{\mathrm{D}} / I_{\mathrm{G}}$ ratio compared to those of the films deposited with carbon nitride target are mainly attributed to the lower $\mathrm{sp}^{3}$ bonding fraction.

\subsection{Mechanical properties}


Fig.7 shows the nanoindentation hardness and elastic modulus of $\mathrm{CN}_{x}$ films deposited at different bias voltages. With the increase of bias voltage, the hardness increases initially and then decreases. Based on the fact that both ratio $x\left(s p^{2}\right) / x\left(s p^{3}\right)$ and $x\left(s p^{2} \mathrm{C}-\mathrm{N}\right) / x\left(s p^{3} \mathrm{C}-\mathrm{N}\right)$ follow exactly the opposite trend, we can conclude that the decrease of the ratio $x\left(s p^{2}\right) / x\left(s p^{3}\right)$ and $x\left(s p^{2} \mathrm{C}-\mathrm{N}\right) / x\left(s p^{3} \mathrm{C}-\mathrm{N}\right)$ makes a significant contribution to improving the hardness of $\mathrm{CN}_{x}$ films [25-27]. The correspondence between bonding configuration and nanoindentation hardness can be explained by the formula $H \sim\left(E_{\mathrm{b}} \times a_{\mathrm{c}}\right) / d^{2}$ (the hardness defined by the product of binding energy $E_{\mathrm{b}}$ and the covalency $a_{\mathrm{c}}$ divided by the square of bond length $d$ ) [46]. The short length and tetrahedrally bonded $\mathrm{sp}^{3}$ hybridization bonding helps to build three-dimensional structure like diamond and makes $\mathrm{CN}_{x}$ films more rigid [47]. However, the maximum film hardness of 8.35 GPa obtained at $-40 \mathrm{~V}(5.1 \mathrm{GPa}$ for the reference films $)$ is much lower than the hardness reported in references [11-13, 48-50]. This indicates that these films exhibit a rather low resistance to penetration. Previous studies $[10,51]$ show that the $\mathrm{CN}_{x}$ film with a nitrogen concentration between 35-50 at.\%, a low density and a polymer-like structure exhibits a rather low hardness and elastic modulus than most films. It is possible that the films deposited at $-80 \mathrm{~V}$ and $-120 \mathrm{~V}$ are similar to these films, because more intense bombardment of species on the film surface leads to a decrease in density and to the structure alteration from compact carbon network to the polymer-like structure.

Fig. 8 shows the mean value of friction coefficient of the $\mathrm{CN}_{x}$ films against $\mathrm{Si}_{3} \mathrm{~N}_{4}$ ball in humid air. At the function of bias voltage, the friction coefficient of the films addresses the highest value of 0.28 at $-40 \mathrm{~V}$ and falls slowly later, but is greater than that of the reference films by $0.02 \sim 0.06$ typically. We believe that, under the same test conditions and tribological mechanism, the $\mathrm{sp}^{2}$ hybridization component is easier to be sheared and contributes to low 
friction coefficient during wear tests, but the $\mathrm{sp}^{3}$ hybridization component presents an opposite action. When the content of $\mathrm{sp}^{3}$ hybridization component decreases in the films, the resistance force in sliding tests decreases and the friction coefficient of the films becomes smaller. Therefore, an increase of the ratio $x\left(s p^{2}\right) / x\left(s p^{3}\right)$ of the films leads to a lower friction coefficient. Therefore, the reference films exhibits a low friction coefficient due to the fact that they have a relatively high level of the $x\left(s p^{2}\right) / x\left(s p^{3}\right)$ ratio, compared to the films deposited with carbon nitride target.

\section{Conclusions}

The microstructure and mechanical properties of the $\mathrm{CN}_{x}$ films prepared by PLD with negative bias voltage and carbon nitride target were studied. The nitrogen content and the fraction of $\mathrm{sp}^{3}$ hybridization bonding in the films are remarkably improved by using the hybrid deposition system. The nitrogen content as well as the $x\left(s p^{2}\right) / x\left(s p^{3}\right)$ and $x\left(s p^{2} \mathrm{C}-\right.$ $\mathrm{N}) / x\left(s p^{3} \mathrm{C}-\mathrm{N}\right)$ ratio of the films are obviously dependent on the bias voltage value. With the increase of bias voltage from $-40 \mathrm{~V}$ to $-120 \mathrm{~V}$, an increased graphitization of the films is observed, accompanied by a decrease of the hardness, the elastic modulus and the friction coefficient of the films. The maximum hardness of $8.35 \mathrm{GPa}$ is obtained with a bias voltage of $-40 \mathrm{~V}$.

\section{Acknowledgements}

The financial supports from Zhejiang Provincial Natural Science Foundation of China (No.Y4110645) are gratefully acknowledged.

\section{References}


[1] A. Y. Liu, M. L. Cohen, Science 245 (1989) 841.

[2] D. G. Liu, J. P. Tu, C. D. Gu, C. F. Hong, R. Chen, W. S. Yang, Surf. Coat. Technol. 205(2010) 2474.

[3] S. Peponas, M. Lejeune, S. Charvet, M. Guedda, M. Benlahsen, Surf. Coat. Technol. 212 (2012) 229.

[4] S. Louring, N. D. Madsen, A. N. Berthelsen, B. H. Christensen, K. P. Almtoft, L. P. Nielsen, J. Bøttiger, Thin Solid Films 536 (2013) 25.

[5] Z. X. Cao, H. Oechsner, J. Vac. Sci. Technol. A 22 (2004) 321.

[6] R. D. Gunning, M. Venkatesan, D. H. Grayson, J. M. D. Coey, Carbon 44 (2006) 3213.

[7] D. K. Lee, D. H. Kang, H. Y. Lee, J. J. Lee. Surf. Coat. Technol. 188 (2004) 440.

[8] M. Aono, S. Aizawa, N. Kitazawa, Y. Watanabe, Thin Solid Films 516 (2008) 648.

[9] X. H. Zheng, J. P. Tu, R. G. Song, Appl. Surf. Sci. 256 (2010) 3211.

[10] C. Popov, L. M. Zambov, M. F. Plass, W. Kulisch, Thin Solid Films 377-378(2000)156.

[11] D. G. Liu, J. P. Tu, H. Zhang, R. Chen, C. D. Gu, Surf. Coat. Technol. 205 (2011) 3080.

[12] C. W. Ong, X. A. Zhao, Y. C. Tsang, C. L. Choy, P. W. Chan, Thin Solid Films 280 (1996) 1.

[13] M. Rusop, T. Soga, T. Jimbo, Diamond Relat. Mater. 13 (2004) 2187.

[14] W. Kulisch, C. Popov, L. Zambov, J. Buliř, M. P. Delplancke-Ogletree, J. Lančok, M. Jelínek, Thin Solid Films 377( 2000) 148.

[15] X. C. Wang, Z. Q. Li, P. Wu, E. Y. Jiang, H. L. Bai, Appl. Surf. Sci. 253 (2006) 2087.

[16] Z. W. Deng, R. Souda, Thin Solid Films 406 (2002) 46.

[17] F. Falk, J. Meinschien, K. Schuster, H. Stafast, Carbon 36 (1998) 765.

[18] H. Ito, K. Kanda, H. Saitoh, Diamond Relat. Mater. 17(2008) 688.

[19] C. B. Cao, H. Wang, H. S. Zhu, Diamond Relat. Mater. 9 (2000) 1786.

[20] H. Habuchi, H. Koketsu, T. Katsuno, Diamond Relat. Mater. 16 (2007) 1340.

[21] Z. J. Zhang, J. L. Huang, S. S. Fan, C. M. Lieber, Mater. Sci. Eng. A 209(1996) 5.

[22] S. Aoqui, T. Ohshima, T. Ikegami, K. Ebihara, Sci. Technol. Adv. Mater. 2(2001) 533.

[23] J. Buliř, M. P. Delplancke-Ogletree, J. Lančok, M. Jelínek, C. Popov, A. Klett, W. Kulisch, Diamond Relat. Mater. 10 (2001) 1901. 
[24] Y. Marumo, Z. D. Yang, Y. W. Chung, Surf. Coat. Technol. 86-87 (1996) 586.

[25] J. J. Li, W. T. Zheng, Z. S. Jin, X. Y. Lu, G. R. Gu, X. X. Mei, C. Dong, Appl. Surf. Sci. 191 (2002) 273.

[26] H. Y. Lee, D. K. Lee, D. H. Kang, J. J. Lee, J. H. Joo, Surf. Coat. Technol. 193 (2005) 152.

[27] P. X. Feng, P. Yang, Y. C. Shi, J. Cryst. Growth 291(2006) 22.

[28] B. Bouchet-Fabre, G. Lazar, D. Ballutaud, C. Godet, K. Zellama, Diamond Relat. Mater. 17 (2008) 700.

[29] L. Y. Feng, R. Z. Min, N. H. Qiao, H. Z. Feng, D. S. H. Chan, L. T. Seng, Ch. S. Yin, K. Gamani, C. Geng, L. Kun, Appl. Surf. Sci. 138 (1999) 494.

[30] K. Yamamoto, Y. Koga, S. Fujiwara, F. Kokai, J. I. Kleiman, K. K. Kim, Thin Solid Films 339 (1999) 38.

[31] S. Lopez, H. M. Dunlop, M. Benmalek, G. Tourillon, M. S. Wong, W. D. Sproul, Surf. Interface Anal. 25 (1997) 315.

[32] Y. S. Jin, T. Shibata, Y. Matsuda, H. Fujiyama, Thin Solid Films 345 (1999) 18.

[33] K. H. Lee, H. Sugimura, Y. Inoue, O. Takai, Diamond Relat. Mater. 13 (2004) 507.

[34] S. Abdelli-Messaci, T. Kerdja, A. Bendib, S. M. Aberkane, S. Lafane, S. Malek, Appl. Surf. Sci. 252 (2005) 2012.

[35] S. M. Park, K. H Lee, Appl. Surf. Sci. 178 (2001) 37.

[36] S. Acquaviva, A. P. Caricato, M. L. De Giorgi, A. Luches, A. Perrone, Appl. Surf. Sci. 110 (1997) 408.

[37] K. Sreejith, J. Nuwad, C. G. S. Pillai, Appl. Surf. Sci. 252 (2005) 321.

[38] K. M. Roh, S. J. You, S. K. Choi, J. H. Kim, D. J. Seong, J. Phys. D Appl. Phys. 42 (2009) 175405.

[39] J. Y. Hao, T. Xu, J. Y. Zhang, W. M. Liu, J. Phys. D Appl. Phys. 39 (2006) 1149.

[40] A. C. Ferrari, S. E. Rodil, J. Roberrtson, Phys. Rev. B 67 (2003) 155306.

[41] Z. P. Wang, H. Ito, K. Masugata, IEEE T. Plasma Sci. 40 (2012) 1815. 
[42] A. Alkhawwam, B. Abdallah, K. Kayed, K. Alshoufi, Acta Phys. Pol. A 120 (2011) 545.

[43] A. C. Ferrari, J. Robertson, Phys. Rev. B 61 (2000) 14095.

[44] F. Alibart, O. Durand Drouhin, M. Benlahsen, S. Muhl, S. Elizabeth Rodil, E. Camps, L. Escobar -Alarcon, Appl. Surf. Sci. 254 (2008) 5564.

[45] A. Alkhawwam, C. Jama, O. Dessaux, P. Goudmand, Thin Solid Film 408 (2002) 15.

[46] X. C. Wang, Z. Q. Li, P. Wu, E. Y. Jiang, H. L. Bai, Diamond Relat. Mater. 15 (2006) 1732.

[47] S. B. Wei, T. M. Shao, J. Xu, Surf. Coat. Technol. 206 (2012) 3944.

[48] G. Beshkov, G. P. Vassilev, M. R. Elizalde, T. Gomez-Acebo, Mater. Chem. Phys. 82 (2003) 452.

[49] W. T. Zheng, H. Ji, W. X. Yu, H. B. Li, Z. S. Jin, Mater. Chem. Phys. 60 (1999) 163.

[50] D. X. Shi, X. F. Zhang, L. Yuan, Y. S. Gu, Y. P. Zhang, Z. J. Duan, X. R. Chang, Z. Z. Tian, N. X. Chen, Appl. Surf. Sci. 148 (1999) 50.

[51] M. A. Baker, P. Hammer, C. Lenardi, J. Haupt, W. Gissler, Surf. Coat. Technol. 97 (1997) 544. 


\section{Figure captions}

Fig. 1 The SEM image of $\mathrm{CN}_{x}$ film deposited at bias voltage of $-40 \mathrm{~V}$

Fig. 2 The $\mathrm{C}_{1 \mathrm{~s}}$ and $\mathrm{N}_{1 \mathrm{~s}}$ XPS spectra of $\mathrm{CN}_{x}$ films deposited by various bias voltages

Fig.3 Dependence of the ratio of $x\left(s p^{2}\right) / x\left(s p^{3}\right)$ in $\mathrm{C}_{1 \mathrm{~s}}$ XPS spectrum and $x\left(s p^{2} \mathrm{C}-\mathrm{N}\right) / x\left(s p^{3} \mathrm{C}-\mathrm{N}\right)$ in $\mathrm{N}_{1 \mathrm{~s}}$ XPS spectrum with negative bias voltage. $x\left(s p^{2}\right)$-Mole fraction of $s p^{2}$ bond, $x\left(s p^{3}\right)$-Mole fraction of $s p^{3}$ bond, $x\left(s p^{2} \mathrm{C}-\mathrm{N}\right)-$ Mole fraction of $s p^{2} \mathrm{C}-\mathrm{N}$ bond, $x\left(s p^{3} \mathrm{C}-\right.$ N) -Mole fraction of $s p^{3} \mathrm{C}-\mathrm{N}$ bond.

Fig. 4 Nitrogen content in the films as a function of bias voltage

Fig. 5 Deconvolution of Raman spectra of the $\mathrm{CN}_{x}$ films deposited at different bias voltages

Fig.6 Variations of the $I_{\mathrm{d}} / I_{\mathrm{g}}, \mathrm{FWHM}$ and position of D band and $\mathrm{G}$ band of the $\mathrm{CN}_{x}$ films with bias voltage

Fig.7 Effects of bias voltage on the hardness and elastic modulus of $\mathrm{CN}_{x}$ films Fig.8 Effects of bias voltage on the friction coefficient of $\mathrm{CN}_{x}$ films 


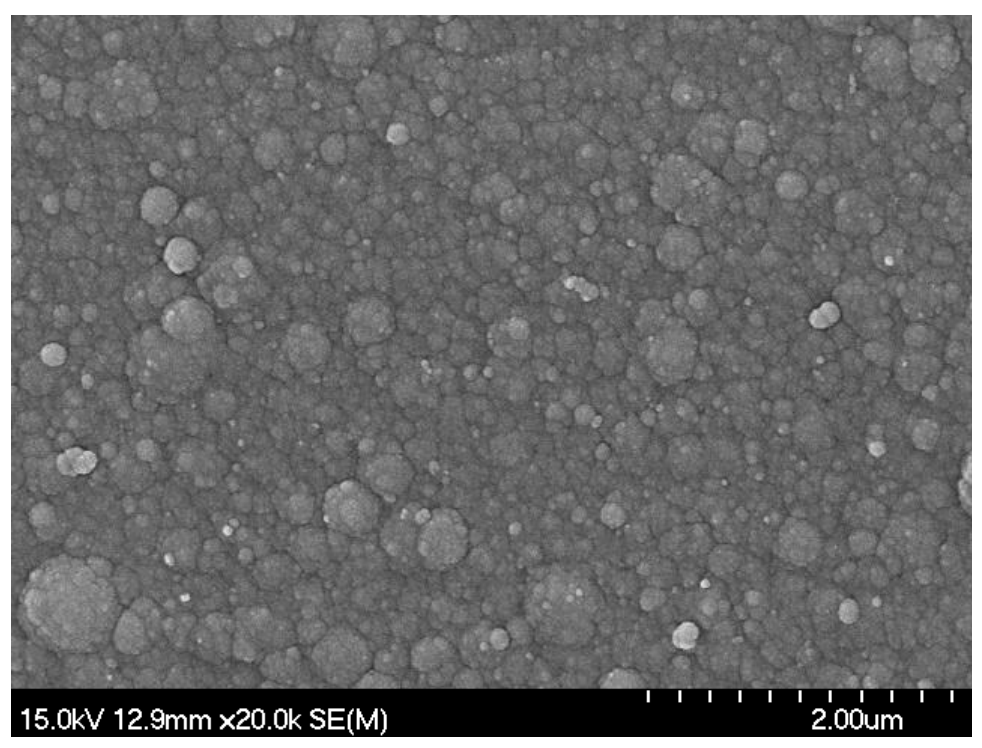

Fig. 1 


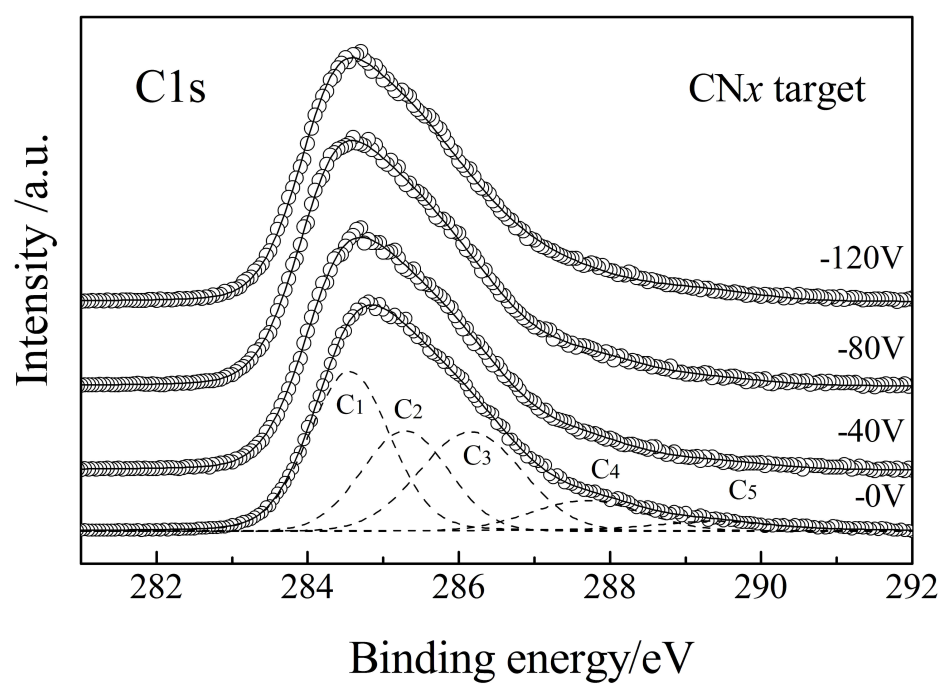

(a) $\mathrm{C} 1 \mathrm{~s}$, Carbon nitride target

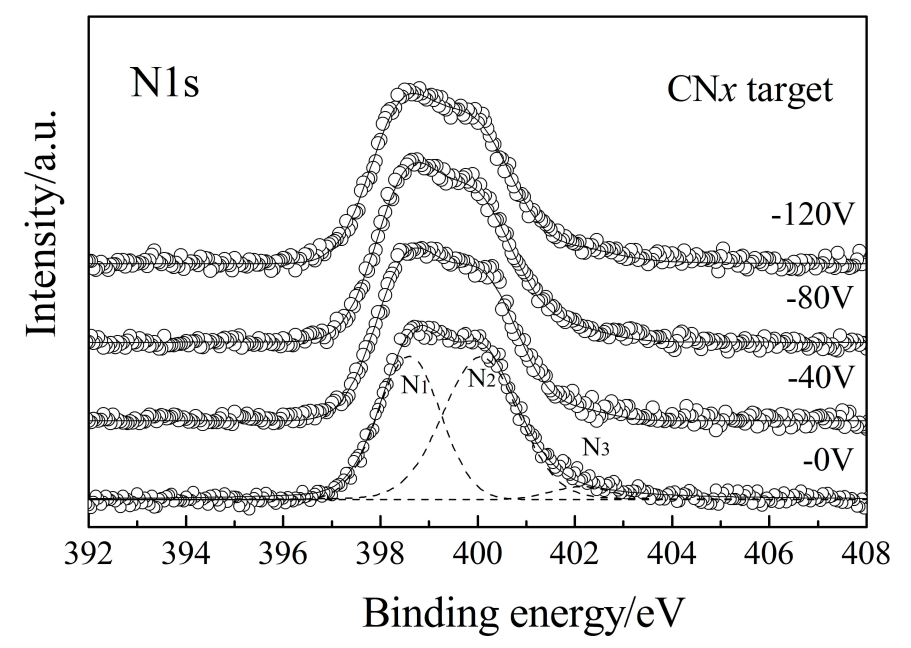

(b) N1s, Carbon nitride target 


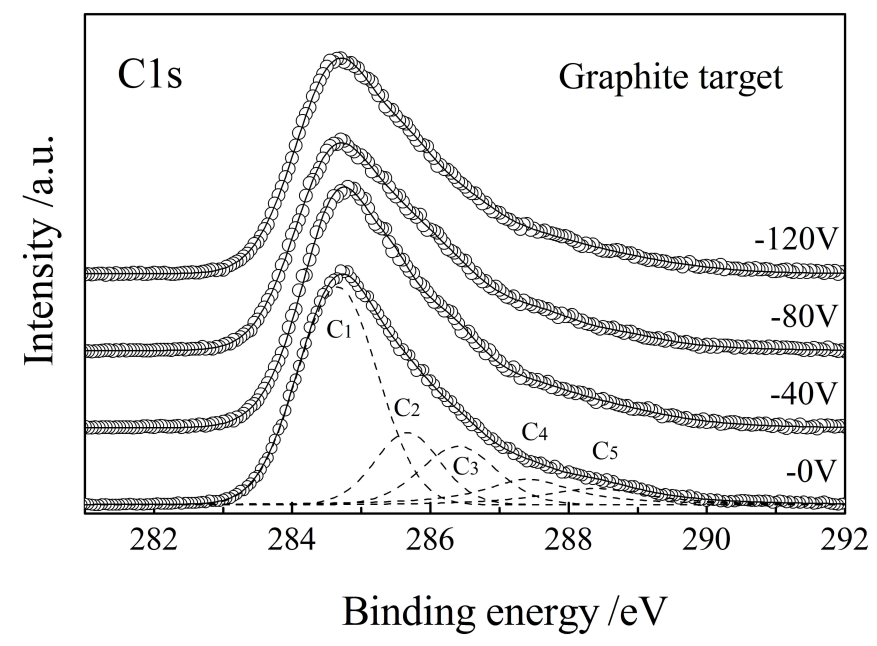

(c) $\mathrm{C} 1 \mathrm{~s}$, Graphite target

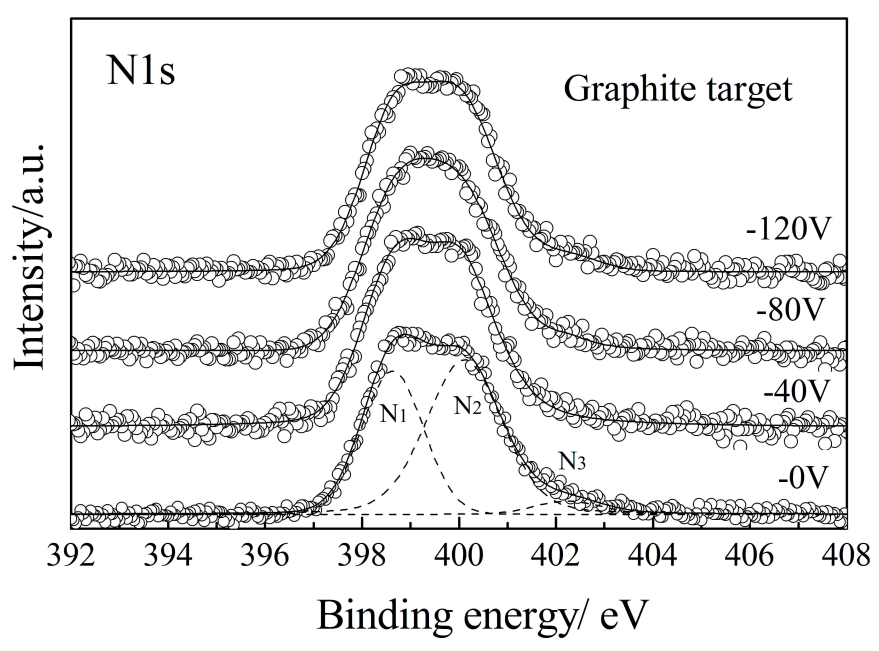

(d) N1s, Graphite target

Fig. 2 


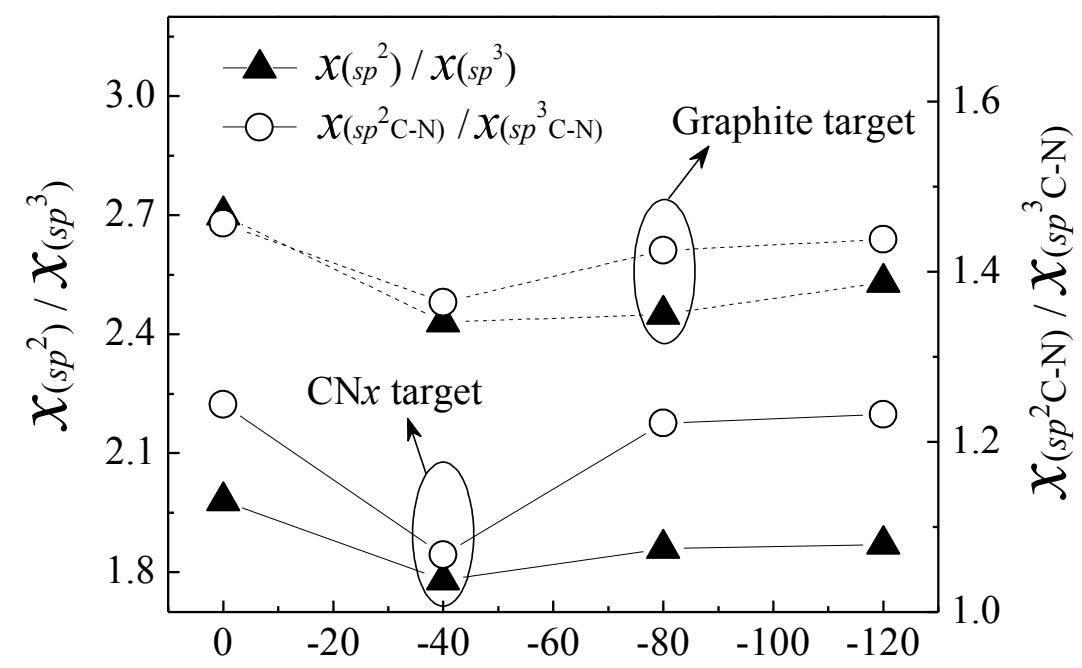

Bias voltage $/ \mathrm{V}$

Fig. 3 


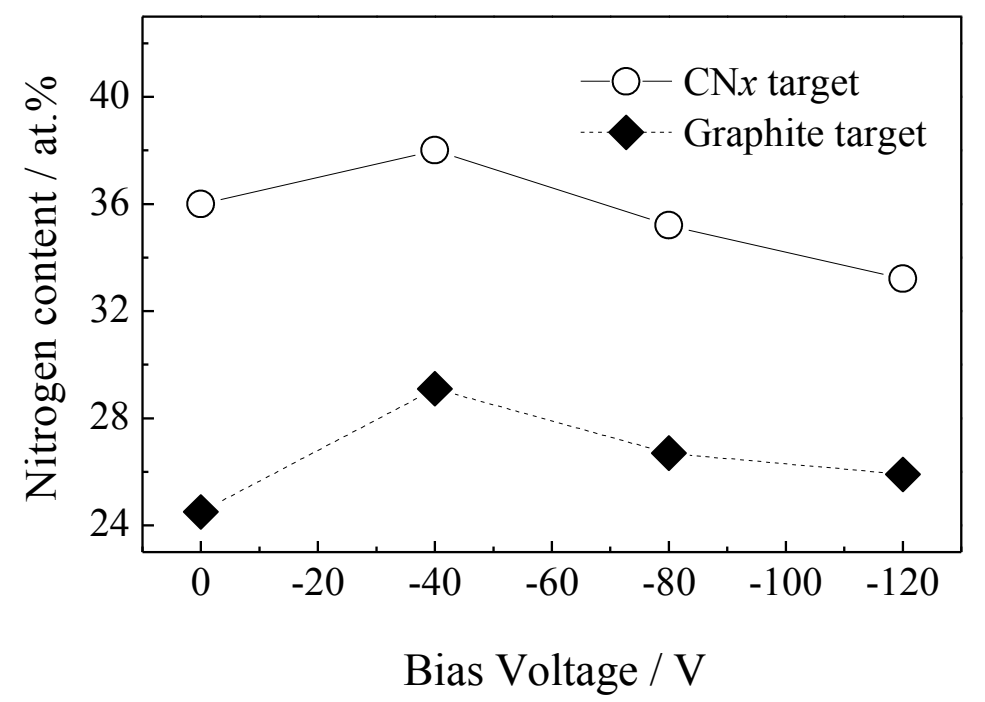

Fig. 4 


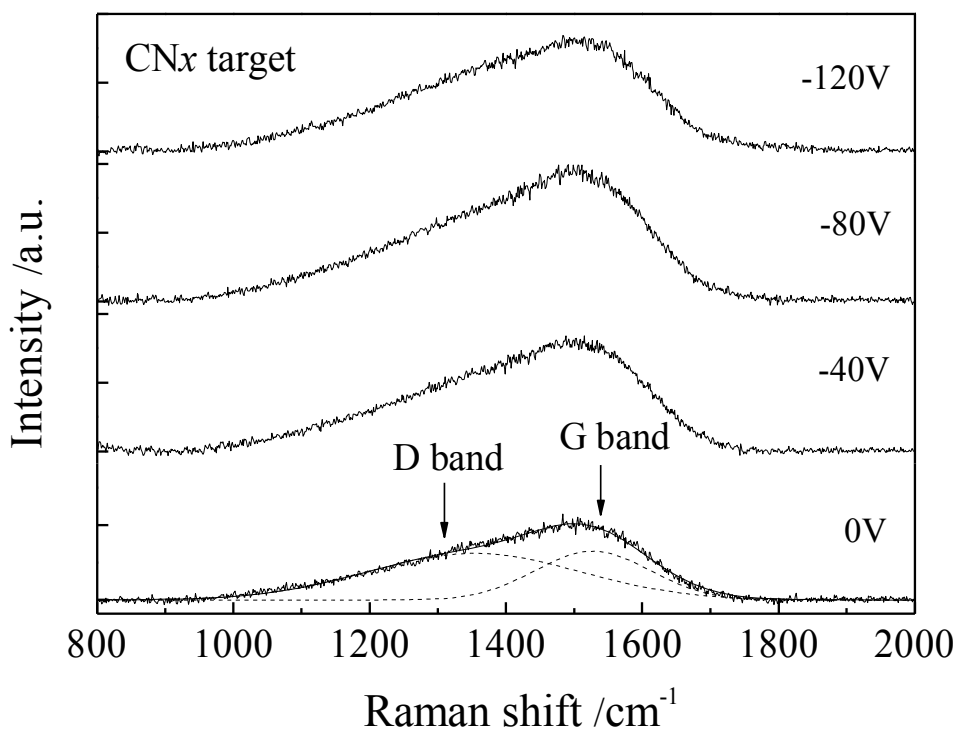

(a) Carbon nitride target

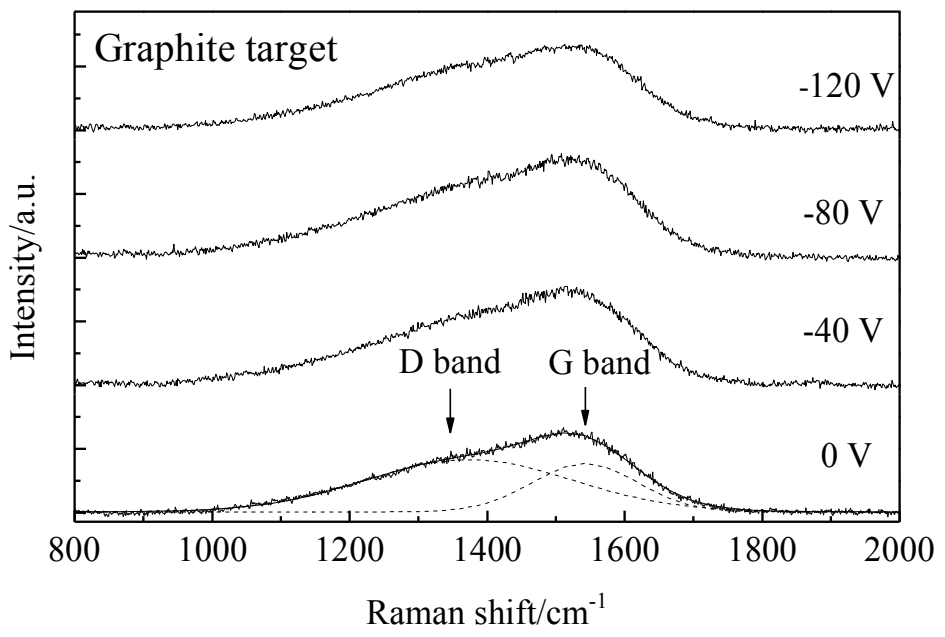

(b) Graphite target

Fig. 5 


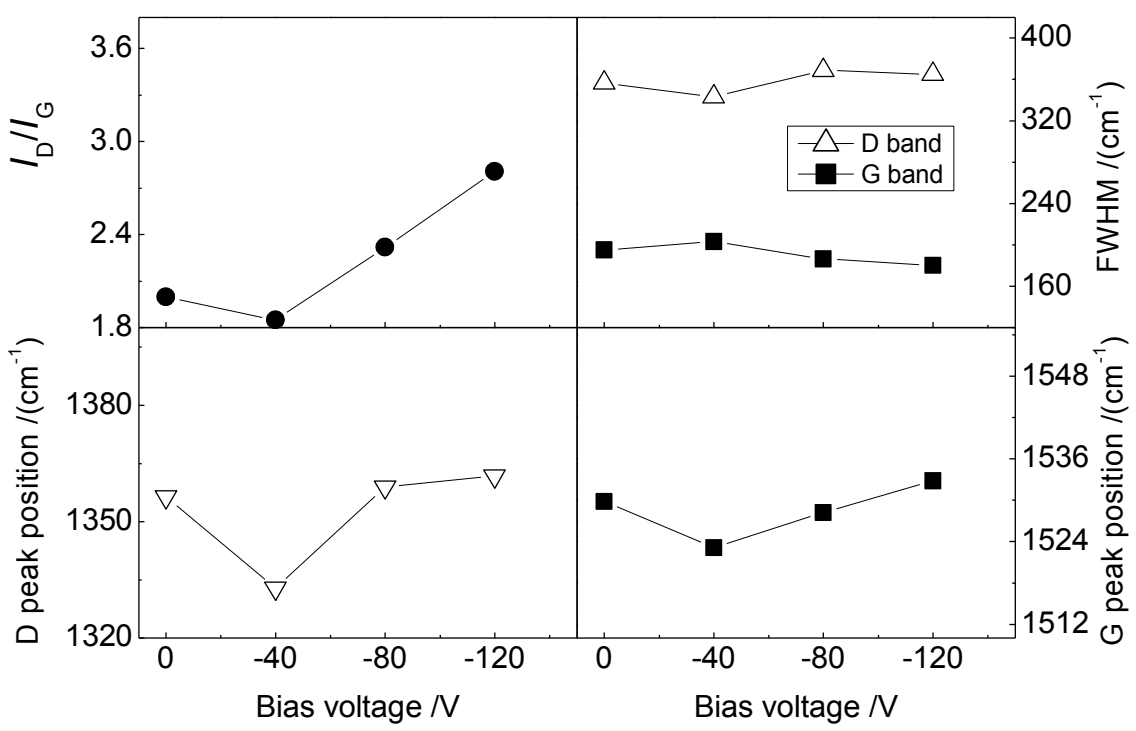

(a) Carbon nitride target

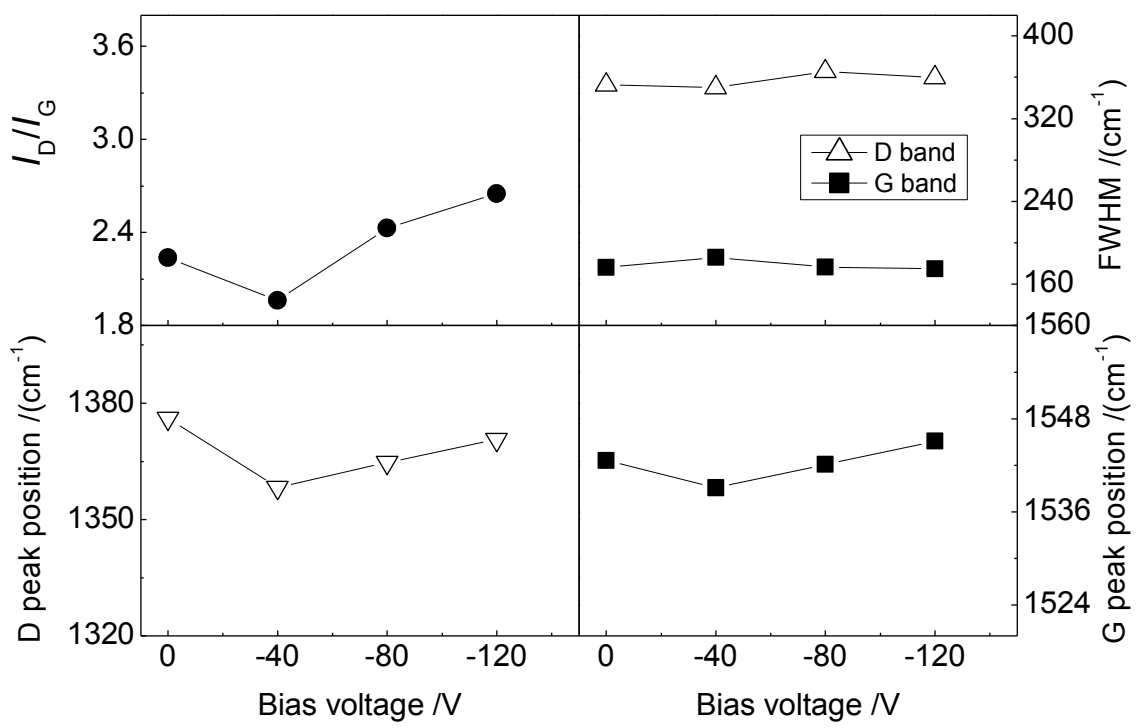

(b) Graphite target

Fig. 6 


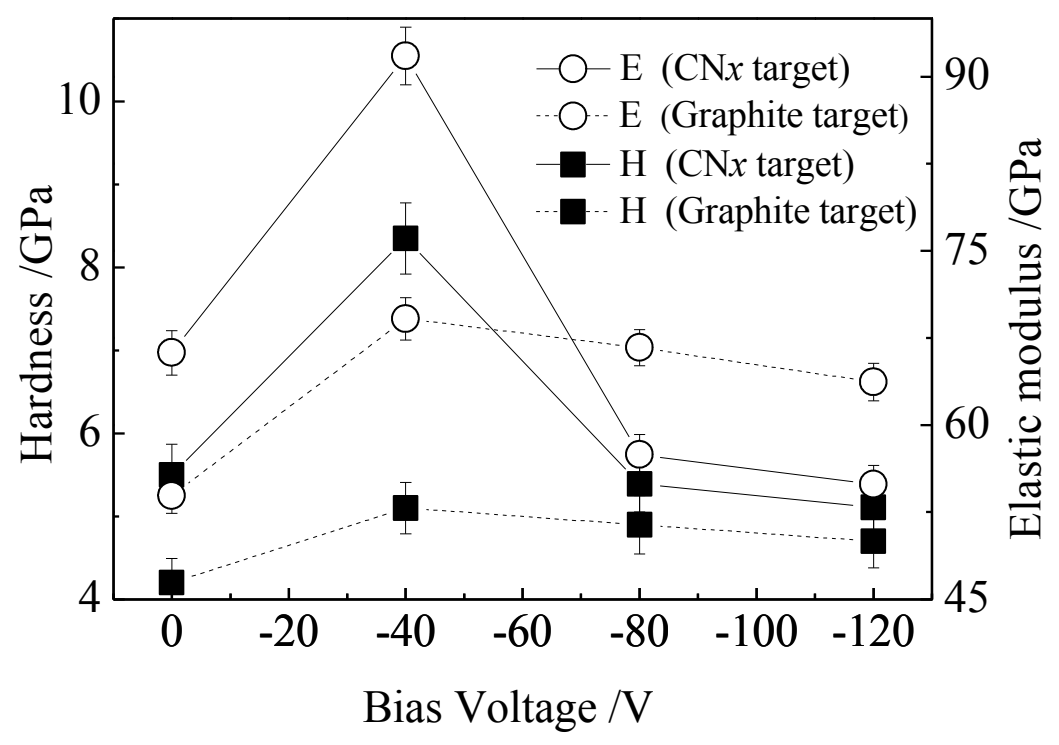

Fig. 7 


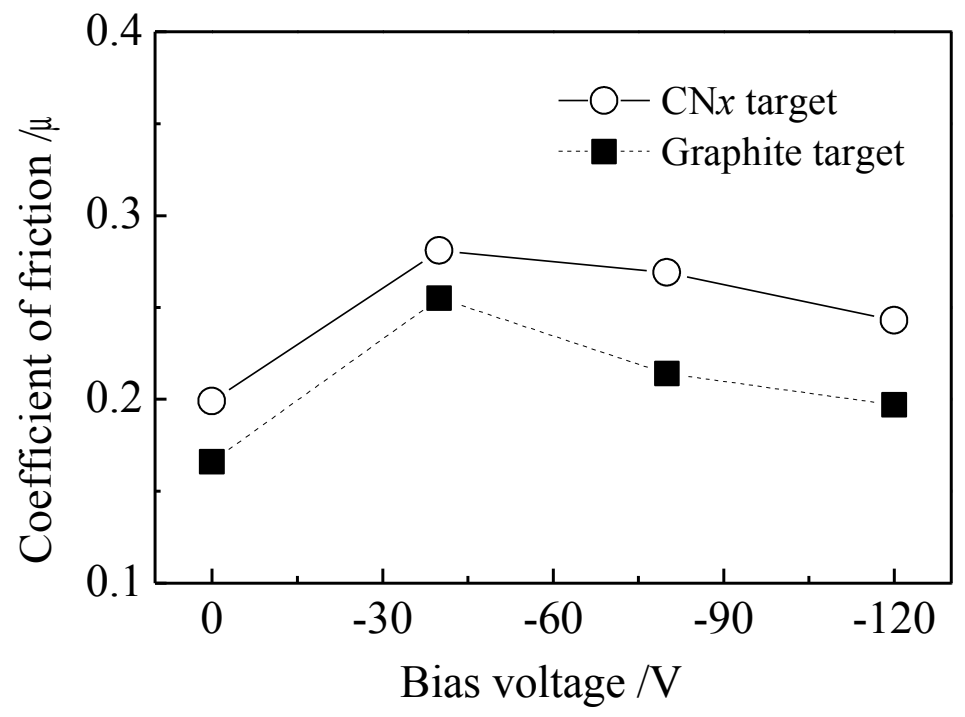

Fig. 8 